\title{
ÉDITORIAL
}

\section{Les réseaux de cancérologie, bilan et perspective}

\author{
J.-P. Gérard
}

Président du réseau OncoPaca-Corse

Président des $5^{\text {es }}$ Assises Nationales des Réseaux de Cancérologie

Créés il y a six ans par le Plan Cancer, encadrés par des textes réglementaires, riches d'une multitude d'expériences régionales, les réseaux de cancérologie arrivent à l'âge de la maturité.

La loi Hôpital-Santé-Patient-Territoire, le nouvel élan du deuxième Plan Cancer, l'importance croissante des réseaux de proximité (ville/établissement de santé), l'évolution du DMP vont nécessairement faire évoluer les missions et le pilotage des Réseaux régionaux de cancérologie.

Les $5^{\text {es }}$ Assises nationales de cancérologie qui se tiennent à Nice les $1^{\text {er }}$ et 2 octobre 2009 en présence de 400 participants sont l'occasion de faire le point sur les actions passées et de parler de l'avenir. Nul doute qu'avec le pilotage de I'INCa, les réseaux régionaux verront leurs missions confortées pour faciliter l'accès de tous à des soins de qualité en cancérologie. Les recommandations et les référentiels, les sites Internet, le futur dossier communiquant en cancérologie et une évaluation régulière seront les outils qui permettront aux réseaux d'accomplir leur mission d'harmonisation et de qualité. 